\title{
Sosyal Paylaşım Ağları, İnternet ve Akıllı Telefona İlişkin Algıların Metaforlar Yoluyla Belirlenmesi
}

\author{
Özlem ÇAKIR ${ }^{1}$ ve Filiz METE ${ }^{2}$
}

\section{Öz}

Metafor, kişisel deneyimlemelerden oluşan yorum farklılıklarının dışavurumudur. Genel olarak dünyayı kavrayışımıza sinen bir düşünce biçimi ve bir görme biçimi anlamına gelir. Her insan bir durumu yaşadığı hayat doğrultusunda farklı şekilde yorumladı̆̆ı gibi bunu ifadelendirmesi de farklı olacaktır. Bu ifade şekli ise metaforun özüdür. Ancak, metaforlar sadece bir söz figürü değil aynı zamanda bir düşünce figürüdür ve bu figürlerin yorumu hayatı doğrudan etkileme gücüne sahiptir. Bu nedenle bir kavramın hedef kitle tarafindan nasıl ve neden böyle algılandığını belirlemek önemlidir. Bu çalışmanın amacı, internet, sosyal dünya ve akıllı telefonlara yönelik alg1ları metaforlar aracıllğıyla belirlemektir. Bu amaç doğrultusunda, internet, akıllı telefon ve sosyal paylaşım ağları (facebook, twitter, instagram gibi) ile ilgili katılımcılardan metaforlar oluşturmaları istenmiş ve oluşturulan metaforların olumlu-olumsuz ve soyutsomut ayrımına göre hangi temalarda yer aldığı ve gruplara göre farklılık gösterip göstermediği araştırılmıştır. Çalışma, betimsel tarama modelinde desenlenmiş ve gerçekleştirilmiştir. Veriler, nitel araştırma yöntemine uygun olarak Doküman İncelemesi tekniği ile elde edilmiştir. Araştırmanın çalışma grubunu 254 katılımcı oluşturmaktadır. Bu çalışmada katılımcılara söz konusu kavramlarla ilgili bir nevi 'alg1 ultrasonu' yapılmış, sonuçlar incelenerek yorumlanmıştır. Araştırma bulguları incelendiğinde; sosyal ağlar ile ilgili oluşturdukları metaforların daha çok olumlu ve somut metaforlar olduğu görülmüştür.

Anabtar Kelimeler: Sosyal paylaşım ağı, Akıllı telefon, Metafor, Alg1

Determining the Perceptions about Social Networking, Internet, and Smartphone through Metaphors

\begin{abstract}
The metaphor is the expression of the differences of interpretation of personal experiences. In general it means a way of thinking and a way of seeing that permeates our understanding of the world. Each person will interpret a situation differently in the direction of the life he / she lives in and it will be different to express it. This form of expression is the essence of metaphor. However, metaphors are not only a word figure but also a thought figure, and their interpretation has the power to influence on the life directly. Therefore, it is important to determine how and why a concept is perceived by the target audience. The aim of this study is to determine the perceptions of internet, social world and smart phones through metaphors. For this purpose, participants were asked to create metaphors related to internet, smartphone and social sharing networks (Facebook, twitter, Instagram) and the themes of the metaphors created according to the positive-negative and abstract-concrete distinctions were investigated. The study was designed and performed in descriptive scanning model. Data were obtained by using Document Analysis technique in accordance with qualitative research method. The study group consisted of 254 participants. In this study, a kind of 'perception ultrasound' was applied to the participants and the results were analyzed and interpreted. When the research findings were examined; it is seen that the metaphors they create about social networks are more positive and concrete metaphors.
\end{abstract}

Key Words: Social network, Smartphone, Metaphor, Perception

\section{Atıf İçin / Please Cite As:}

Çakır, Ö. ve Mete, F. (2020). Sosyal paylaşım ağları, internet ve akıllı telefona ilişkin algıların metaforlar yoluyla belirlenmesi. Manas Sosyal Arasturmalar Dergisi, 9(1), 261-273.

Geliş Tarihi / Received Date: 16.02.2019

Kabul Tarihi / Accepted Date: 03.09.2019

\footnotetext{
${ }^{1}$ Doç. Dr. - Türkiye-Ankara Üniversitesi Eğitim Bilimleri Fakültesi, ocakir@ankara.edu.tr - ORCID: 0000-0002-7306-5820

2 Doç. Dr. - Türkiye- Hacettepe Üniversitesi Eğitim Fakültesi, filizmete@hacettepe.edu.tr - ORCID: 0000-0002-8835-3884
} 


\section{Giriş}

Metafor terimi, Latince "metafora” kökünden gelmektedir. Öte, aşırı anlamına gelen meta ve taşımak, yüklenmek anlamına gelen pherein sözcüklerinin birleşiminden oluşmaktadır. Metafor, kişisel deneyimlemelerden oluşan yorum farkllıklarının dışavurumudur. Morgan'a (1998, s. 14) göre metafor kullanımı, genel olarak dünyayı kavrayışımıza sinen bir düşünce biçimi ve bir görme biçimi anlamına gelir.

Metaforla ilgili 1980’lerden itibaren yapılmış özellikle sosyal bilimlerin farklı alanlarında pek çok çalışma mevcuttur. Shuell (1990, s. 102) oluşturulan bir metaforun, bir olgu hakkında düşünmek için zihinsel bir çerçeve sunduğunu belirtir. Metaforlar, kişinin evrene ait unsurları kendi duygu ve düşünce süzgecinden geçirerek yansıtmasıdır (Mete ve Ayranc1, 2016, s. 54). Böylece kişi, bu dünyaya ait imgeleri kendi algılayışıyla ifade etmektedir. Arslan ve Bayrakçı (2006, s. 103) metaforun, bireyin kendi dünyasını anlaması ve yapılandırmasına yönelik güçlü bir zihinsel haritalama ve modelleme mekanizması olduğunu belirtmektedir.

Yapılan çalışmalar arasında metaforların bilimde kuram oluşturmada, örgütlerin stratejik yönelimlerini değiştirmede, çalışanların çalıştıkları örgütleri nasıl algıladıkları, örgütsel değişimi açıklamakta nasıl aynı görevi gördükleri konularında iş dünyasına veri sağlamak üzere yapılan pek çok çalışma mevcuttur. Eğitim alanında ise çocukların öğrenmelerini kolaylaştıran araçların nasıl kullanılabileceği, öğretmenlerin öğrencilerini nasıl algıladıkları, öğrencilerin dersleri nasıl algıladıklarıyla ilgili çok sayıda çalışma vardır (Çelikten, 2005, s. 270). Örneğin; Erdem (2010) metaforların atasözlerinde işleyişini, Aktekin (2013) öğretmen ve öğrencilerin tutum ve inançlarını, Mertol, Doğdu, Yılar (2013) üstün zekâlı ve yetenekli öğrencilerin sosyal bilgiler dersine ilişkin algılarını, Ceran (2015) Türkçe öğretmeni adaylarının Türkçe ders kitaplarına ilişkin görüşlerini, Sevim, Veyis ve Kınay (2012) lisans öğrencilerinin Türkçe algılarını, Özbaş ve Aktekin (2013) öğretmen adaylarının tarih öğretmenliğine dair inançlarını, Karaçanta (2013) lisans öğrencilerinin millî değerlere yönelik algılarını, Özdemir ve Akkaya (2013) öğrenci ve öğretmenlerin okul ve ideal okul algılarını, Altıntaş, Kahraman, Ülger ve Altıntaş (2014) fen ve teknoloji dersi kapsamında bir ünitedeki kavramlar üzerine öğrencilerin algılarını belirleme gibi daha birçok çalışma yapılmışır. Yob’un (2003, s. 134) da vurguladığ gibi: "Temelde metafor, söz ettiği olgunun kendisi değildir, onun sadece bir sembolüdür. Mete ve Ayranc1 (2016) dil ve edebiyata ilişkin algıların metaforlar yoluyla incelenmesi adlı çalışmalarında bir nevi 'alg1 ultrasonu' gerçekleştirdiklerini ve bireydeki mevcut durumun belirlenmesinin eğitim öğretim sürecindeki iyileştirme ve geliştirme çalışmalarına olumlu katkısı olacağını vurgulamışlardır. $\mathrm{Bu}$ çalışmada da metaforlar yoluyla bireylerin internet, sosyal paylaşım ağlarıyla sanal dünya ve internet bağlantılı akıllı cep telefonlarılya ilgili algıları belirlenmiştir.

Günümüzde teknoloji, yaşamın değişilmez bir parçası hâline gelmiştir. İnsan, toplu yaşam ihtiyacı hisseden sosyal bir varlıktır. Sosyalleşme ihtiyacını bir araya gelerek karşılar. Ancak değişen teknolojik dünyada sosyalleşme mekânları ve olanakları da çağa ayak uydurmuş ve zaman, mekân ve mesafe sınırlılıkları yok edilmiştir. Böylece sosyalleşme mekânları sosyal paylaşım ağları hâline gelmiştir. Sosyalleşmenin Yeni Yüzü: Sosyal Paylaşım Ağlarıdır (Dilmen ve Ögüt, 2006). 7/24 dünyanın her yerine ve herkesle iletişim imkânı insanı cezbetmiş ve sanal mekanlarda bağlantıya bağımlı hâle getirmiştir. Özellikle de mobil teknolojilerin ve bu teknolojilerin kullanıcı boyutunda akıllı telefonların kullanımı hızlı bir şekilde yaygınlaşmaktadır. Eskiden kullanılan cep telefonlarının yerini almaya başlayan akıllı telefonlar sayesinde, iletişime ek olarak, akıllı telefonların taşıdığ1 sosyal ağ uygulamaları, adres defteri, veri depolama birimi, video- kamera, zaman işlemleri (saat, takvim, süreölçer vb.), video oynatıc1, navigasyon cihazı ve son zamanlarda uçak bileti ya da kredi kartı gibi özellikleri sayesinde bireylerin birçok işlemi yapması kolaylaşmıştır. Ayrıca mobil internetin yaygınlaşması, kablosuz internete erişim kolaylığı, akıllı telefonların kapasitesinin daha da artması (hız, kapasite, işletim sistemi vb.) ve mobil cihaz fiyatlarının düşmesi de akılllı telefon kullanımının yaygınlaşması sebepleri arasında gösterilebilir. We Are Social (2015) tarafından hazırlanan İnternet ve Sosyal Medya Kullanıcı İstatistiklerine göre Türkiye de dâhil olmak üzere 30 ülkenin internet kullanıcı sayısı geçtiğimiz yıla kıyasla 525 milyon artış ile dünya üzerindeki yaklaşık 3 milyar kişinin internete bağlanabilir olduğunu göstermiştir. Aynı rapora göre Türkiye'de yaklaşık 69,6 milyon mobil kullanıcı bulunduğu belirtilmiştir. Türkiye İstatistik Kurumu [TUIK] (2015) tarafindan yapılan araştırmada ise hanelerin \% 96,8'inde cep telefonu bulunduğu görülmektedir. Aynı rapora göre internet kullanan bireylerin oranı \% 55,9 olarak verilmiştir. Türkiye genelinde internet erişim imkânına sahip hanelerin oranı ise 2015 yll Nisan ayında \% 69,5 olarak verilmiştir. İnterneti 2015 yllının ilk üç ayında kullanan bireylerin $\% 74,4$ 'ü hane ve işyeri dışında internete kablosuz olarak bağlanmak için cep telefonu veya akı1lı telefon kullanırken, \% 28,9'unun taşınabilir bilgisayar (dizüstü, netbook, tablet vb.) kullandığı rapor edilmiştir. Günlük kullanım oranlarına bakıldığında Türkiye'deki internet kullanıcıları gün içerisinde ortalama 4 saat 
37 dakikayı internette, 2 saat 51 dakikayı mobil internette ve 2 saat 56 dakikayı ise sosyal medyada geçiriyor (We Are Social, 2015). Görüldüğü gibi akıllı telefonların ve kablosuz internet erişiminin yaygınlaşması, hem internetin hem de akıllı telefonların kullanımını artırmıştır.

Mobil cihazlar genç nüfus arasında daha yaygın bir şekilde kullanılmaktadır (Kennedy et al. 2008). Bu durumu genç kuşağın gündelik yaşamlarında teknolojiyi kullanmayı fazlası ile benimsemesine, dolayısıyla da gençlerin gelişen yenilikleri toplumun her kesiminden daha önce takip etmelerine bağlayabiliriz (Karaaslan ve Budak, 2012). Buna ek olarak 18-29 yaş arasında Amerikan genç nüfusunun \%15'inin, internet erişimi için ağırlıklı olarak akıllı telefonlara bağımlı olduğu tespit edilmiştir (Smith, 2015). Bireyler yoğun olarak akıllı telefonlar ve tablet bilgisayarları, internet erişimi, sosyal ağlar, müzik dinlemek, video seyretmek gibi faaliyetler için kullanmalarına rağmen, son dönemlerde mobil teknolojiler eğitim-öğretim faaliyetlerinde de formal ya da informal olarak kullanılmaya başlanmıştır. Özellikle mobil cihazlar bilgi depolama, ders materyalleri, elektronik kitaplar, ders dağıtım tabloları ve bilgiye erişim için tercih edilmektedir (Sarrab, 2015). Chen ve Denoyelles (2013), mobil teknolojilerin üniversite öğrencilerin akademik yaşamlarında artan bir şekilde önemli bir rol oynadığını belirtmişlerdir. Yang, Hwang, Hung ve Tseng (2013), kablosuz ve mobil teknolojilerdeki son zamanlardaki gelişmelerin yeni eğitim deneyimleri ve bilgi edinme faaliyetlerine olanaklar sağladığını ifade etmektedir. Mobil öğrenme diye tanımlanan bu yeni eğitim tecrübesi ve yaklaşımı, mobil cihazlar ile eğitim içeriklerinin entegre edilmesi ve böylece mobil cihazlar üzerinden her an, her yerden bilgiye ve eğitim içeriklerine ulaşım anlamına gelmektedir (Garry Wei-Han, Keng-Boon, Lai-Ying ve Binshan, 2014; Toteja ve Kumar, 2012). Berson ve Berson (2003), internetin genç bireylerin bilgiye ulaşmalarını, araştırma yapmalarını kolaylaştıran, bu sayede problem çözme yaratıclık, kritik düşünme gibi becerilerin gelişimini destekleyen bir kaynak olduğunu ifade etmektedir. Aynı şekilde, internetin akademik anlamda gençler ve yetişkinler için diğer insanlarla iletişim ve bilgiye hemen ulaşma açısından önemli bir araç olduğu ifade edilmektedir (Ko vd., 2012).

Akıllı telefonların ve internetin kullanımının günlük hayatı her alanda kolaylaştırdığı bir gerçektir. Fakat teknolojinin amacı dışında ve aşırı kullanılması, birtakım fiziksel, davranışsal ve psikolojik sorunları da beraberinde getirmektedir. Gezgin (2018) tarafindan yapılan bir çalışma uyku süresi ile akıllı telefon kullanımı arasında negatif bir iliş̧ki olduğunu ortaya koymuştur. Çalışmaya göre akıllı telefonların aşırı kullanımı ve bağımlılık yüzünden bireylerin geç saatlere kadar uyumadığı ve ertesi gün bireylerin bu durumdan hayata konsantrasyon açısından olumsuz etkilendiği rapor edilmiştir. Örneğin, bireylerde bağımlılık oluşturarak depresyon, düşük öz sayg1, aşırı hassaslık, suçluluk, umutsuzluk gibi olumsuz davranışlara neden olabilmektedir. King ve meslektaşlarının 2014 yllında Brezilya'da gerçekleştirdikleri araştırmada, panik bozukluğu olan hastaların mobil telefon kullanımı kaynaklı duygu değişimleri ve semptomları incelenmiştir (King vd., 2014). Toplam 120 kişinin katıldığ1 deneysel çalışmada, hem panik bozukluğu olan hastalardan oluşan grubun hem de sağllklı kontrol grubun mobil telefona 'bağımlılık' gösterdiği, ancak panik bozukluğu olan hastalarda mobil cihaz kullanamamanın daha yoğun duygu değişimlerine, fiziksel ve psikolojik semptomlara yol açtı̆̆ ifade edilmektedir. King ve diğgerleri (2014), mobil telefon bağımlılığının kişilerde sosyal fobi veya bağımlı kişilik bozukluğu gibi primer bir bozukluğun varlı̆̆ına işaret ettiğine yönelik çalışmalara da atıfta bulunmaktadır.

Samaha ve Hawi (2016), 300 üniversite öğrencisi üzerinde yaptıkları çalışmada, akıllı telefon bağımlılığı ile stress düzeyleri arasında pozitif bir ilişkinin varlığını ortaya çıkarmışlardır. Aynı zamanda literatürde bazı çalışmalarda ögrencilerin akademik performansı ile mobil telefon kullanımı arasında negatif bir ilişki olduğu da tespit edilmiştir Judd, 2014; Karpinski vd., 2013; Rosen vd., 2013; Samaha ve Hawi, 2016; Wentworth ve Middleton, 2014; Kibona ve Mgaya, 2015; Gezgin, Hamutoğlu, Samur ve Yıldırım, 2018). M-öğrenme kavramı içerisindeki akıllı telefonların yerini tartışan Spitzer (2015) akıllı telefonların eğitim ortamlarında çoğu zaman göz ardı edilen risk ve yan etkilerine çeşitli ülkelerde gerçekleştirilen 22 çalışmadan elde edilen sonuçlar aracıllğıyla dikkat çekmiştir: bağımlılık, dikkat bozukluğu, empati bozukluğu, öğrenmenin sekteye uğraması sonucu eğitim başarısında düşüş, hipertansiyon, obezite, kayg1, depresyon, kişilik bozukluğu, agresyon, tatminsizlik ve yalnızlık gibi. Literatürde de teknolojinin aşırı ve problemli kullanımından doğan bir çok psikolojik sendrom bulunmaktadır.

Son yıllarda mobil cihazlar bireylerin hayatlarına büyük ölçüde yön vermeye başlamıştır. İlk zamanlarda sadece telefon görüşmesi ve kısa mesaj gönderimi gibi fonksiyonları içeren bu cihazlar günümüzde büyük bir değişim sürecine girmiştir. Bilgi ve iletişim teknolojileri arasında en yaygın olarak kullanılanları dizüstü bilgisayarlar, tablet bilgisayarlar ve akıllı cep telefonları olarak sayılabilir (Özbek, Alnıaçık, Koç, Akkılıç ve Kaş, 2014). Mobil cihazlar arasında akıllı telefonlar (smartphone) artık bir 
bilgisayardan farksız hâle gelmiştir (Ada ve Tatlı, 2013). Türkiye İstatistik Kurumu verilerine göre 2010 yıllında dünya çapında 305 milyon adet akıllı telefon satısı (Noyan, Enez-Darçın, Nurmedov, Yılmaz ve Dilbaz, 2015), 2013 yllında 1.04 milyar adet satışa ulaşmıştır (Özbek, Alnıaçık, Koç, Akkılıç ve Kaş, 2014). Akıllı telefonlara eklenen yeni özellikler, kolay taşınabilirlik gibi nedenlerden dolayı akıllı telefonların gittikçe yaygınlaşması çok doğaldır. Akıllı telefonlar ile telefon görüşmesi, kısa mesaj gibi normal telefonlarla yapılabilen işlemler yanında; görüntü ve ses kaydı, verilerin iletimi, internet erişimi, e-mail, anlık mesajların iletimi, dijital içeriğin görüntülenmesi, mobil uygulamalar, sosyal medya araçları, oyun gibi birçok uygulama kullanılabilmektedir. Günümüzde mobil telefonlar bireylerin günlük yaşamlarının önemli bir parçası hâline gelmiş ve diğer bireylerle bağlantı kurmak (Leena, Tomi ve Arja, 2005), aile üyeleri ve arkadaşları aramak, mesaj göndermek, mümkün olan her yer ve zamanda onlarla bağlantilı olmak, internete bağlanmak, oyun oynamak ve müzik dinleyip hoş vakit geçirmek (Coogan ve Kangas, 2001) için zorunlu bir araç olarak görülmeye başlanmıştır (Şar ve Işıklar, 2012). Ülkemizde 2011 yllındaki internet kullanım oranı \% 42,9 olup bunun \% 4'ü ak1llı telefonlarla elde edilmekteyken, 2013 yllındaki internet kullanım oranı yaklaşık \% 49 olup bunun \% 16'sı telefonlardaki mobil bağlantılar yoluyla gerçekleşmiştir (TUIK, 2013). Akıllı telefon kullanımında gözlenen durum, özellikle çocukların ve ergenlerin kullanımının yaygın olmasıdır. Türkiye İstatistik Kurumunun yaptırdığ1 bir araştırma (2010) Türkiye'de yaşayan bireylerin cep telefonu sahibi olma oranının özellikle yoğunluğu oluşturan genç nüfus olmak üzere yaklaşı \% 90 olduğunu göstermiştir; bu oran kentlerde \% 92,8 ve kırsal alanda \% 85'tir. Bu da cep telefonunun gençler arasında oldukça yaygın olduğunu göstermektedir (Şar, 2013). Önceden internet bağımlllı̆̆ kavramı ön plandayken, şimdilerde bu kavramın yerini akıllı telefon bağımlılı̆ı kavramı almışır (Kwon, Kim, Cho ve Yang, 2013). Bu yaygın kullanım, internet, oyun ve telefon bağımlısı olan kişilerin bağımlılıklanını pekiştirirken, bağımlı olmayanların da bağımlı olmalarına neden olabilmektedir (Demirci, Orhan, Demirdaş, Akpinar ve Sert, 2014). Türkiye'de kullanımı giderek artan akıllı telefonların kontrolsüz ve aşırı kullanımına ilişkin çalışmalar, bu durumu değerlendirmek üzere yapılan ölçeklerin geçerlilik ve güvenilirlik çalışmalarıyla sınırlıdır. Akıllı telefon bağımlılığı tanımı, tanı ölçütleri, risk etkenlerinin ortaya konabilmesi, önleme ve tedavi girişimleri yapılabilmesi için akıllı telefonların kullanımı ve risk değerlendirme ile ilgili çalışmalara gerek vardır. Bu çalışmalarda kullanılabilecek, Türkçeye uyarlanmış ölçek sayısı sınırlıdır. Akıllı/mobil telefon bağımlılığını değerlendirmeye yarayan ölçekler genellikle Doğu Asya ülkelerinde geliştirilmektedir (Noyan, Enez-Darçı, Nurmedov, Yılmaz ve Dilbaz, 2015).

Gelişen teknolojinin kullanımı günlük hayatı kolaylaştırırken aşırı kullanımının insanları olumsuz etkilediği de yadsınamaz bir gerçektir. Buna verilecek iyi örneklerden biri ise bilgisayarın amacı dışında gereğinden fazla kullanılmasıdır. Aşırı kullanım ciddi fiziksel ve psikolojik sorunlara yol açabilen önemli bir problemdir.

Bu çalışmanın amacı, bireylerin internet, sosyal dünya ve akıllı telefonlara ilişkin algılarını metaforlar aracilığyla belirlemektir. Bu algilardan yola çıkarak bireyin hayatına etkisi ve yansıması tespit edilebilecektir. $\mathrm{Bu}$ amaç doğrultusunda, aşağıdaki sorulara cevap aranmıştır:

1. Sosyal ağlarla ilgili oluşturulan metaforlar, olumlu-olumsuz ve soyut-somut ayrımına göre hangi temalarda yer almaktadır?

2. İnternet bağlantısıyla ilgili oluşturulan metaforlar, olumlu-olumsuz ve soyut-somut ayrımına göre hangi temalarda yer almaktadır?

3. Ak1llı telefonlarla ilgili oluşturulan metaforlar, olumlu-olumsuz ve soyut-somut ayrımına göre hangi temalarda yer almaktadır?

4. Oluşturulan metaforların olumlu veya olumsuz olması gruplara göre farkl11ık göstermekte midir?

\section{Yöntem}

Bireylerin sosyal hayatla ilgili metafor kullanımını belirlemeyi amaçlayan bu araştırma betimsel tarama modelinde desenlenmiş ve gerçekleştirilmiştir. Çalışma boylamsal olarak ele alınmış ve temel (6-12 yaş aras1); orta (13-19 yaş arası) ve üst (20 + yaş) yaş gruplarındaki temel eğitimden yükseköğretime bütün aşamalardan katılımcıları kapsamasına özen gösterilmiştir. Veriler, nitel araştırma yöntemine uygun olarak Doküman İncelemesi tekniği ile elde edilmiştir. Nitel kelimesi, içeriklerdeki detayların ve niteliklerin titizlikle incelenmesi gerektiğine vurgu yapmaktadır. Nitel araştırmalarda sosyal tecrübenin nasıl yaratıldığ1 ve bu tecrübelere nasıl anlam verildiği sorusuna cevap aranır (Denzin ve Lincoln 2011).

\section{Çalışma Grubu}

Araştırmanın çalışma gurubunu Ankara'da yaşayan bireyler oluşturmaktadır. Katılım için hiçbir yaptırım uygulanmamış, gönüllülük esas alınmıştır. Katılımcılar yaş seviyelerine göre aşamalı olarak temel 
grup (6-12 yaş aras1); orta grup (13-19 yaş arası) ve üst gruptan (20 + yaş) oluşmaktadır. Böylece toplam katılımc1 sayısı 254 olmuştur.

Tablo 1. Katılimcı Bilgileri $(n=254)$

\begin{tabular}{llcc}
\hline & & $f$ & $\%$ \\
\hline \multirow{2}{*}{ Cinsiyet } & Kadın & 122 & 48.04 \\
& Erkek & 132 & 51.96 \\
\hline \multirow{2}{*}{ Seviye } & Temel & 85 & 33.47 \\
& Orta & 101 & 39.76 \\
& Üst & 68 & 26.77 \\
\hline
\end{tabular}

Tablo 1'de görüldüğü gibi çalısmada 122 kadın, 132 erkek katılımcı mevcuttur. Katılımcıların; Temel grubu 85, Orta grubu 101, Üst grubu 68 olmak üzere toplam 254 bireydir.

\section{Veri Toplama Araçları}

Metaforlar, bireylerin belli bir olguya ait sahip oldukları zihinsel imgeleri tespit etmede, anlamada ve açıklamada bir araștırma aracı olarak kullanılabilmektedir (Kaya, 2014). Bu çalışmada bireylerin sosyal hayata ilisskin metaforik algılarını tespit etmek amacıyla araştırmacılar tarafından bir form hazırlanarak veri toplama aracı olarak kullanılmıştır.

Formda aşağıdaki cümleler yer almıştır.

1. Sosyal paylaşım ağlar (facebook, twitter, instagram vs.) benim için.............. gibidir, çünkü...........

2. Internet benim için................... gibidir, çünkï....................

3. Internet bağlantım olmadiğında kendimi ............. gibi bissediyorum, çünkü̈................

4. Telefonum benim için ................... gibidir, çünkï ...................

5. Telefonum olmadiğında kendimi........... gibi hissediyorum, çünkü.............

\section{Verilerin Toplanmas1}

Bireylerden, 20 dakikalık sürede her boşluk için bir metafor bulmaları ve "çünkü" ile devam eden cümleyi tamamlayarak bir "gerekçe" sunmaları istenmiştir. Kavramla ilgili herhangi bir yönlendirme güvenilirliği etkileyeceği için içerikle ilgili herhangi bir açılama yapılmamış ancak beklentinin ne olduğunu daha açık anlatabilmek için temel gruptaki öğrencilere farklı bir konuda oluşturulan örnekler verilerek daha ayrıntılı açıklamalar yapılmıştır.

\section{Verilerin Analizi}

Katılımcılar tarafından oluşturulan metaforlar aşağıdaki aşamalarda analiz edilmiştir:

1. Kodlama: İlk aşamada katılımcılar ait oldukları gruplara göre sıralanmıştır. Daha sonra ise katıllımcılar tarafından oluşturulan metaforlar alfabetik sıralanmış ve kodlanmıştır.

2. Ayıklama: $\mathrm{Bu}$ aşamadaki ayıklama işlemi, bir metafor kullanıldı̆̆ hâlde herhangi bir gerekçe açıklanarak kavram ve metaforla ilişkilendirme yapılmayan kağıtların belirlenerek çalışma dışında birakilmasıdır.

3. Kategori geliştirme: Çalışmanın veri analiz sürecine yön verecek gerekçelendirilmiş metaforlar irdelenerek karşıllk bulacağı ana temalar belirlenip kategorilere ayırma ve gruplandırarak yorumlama basamağı araştırmacılar tarafından bu aşamada gerçekleştirilmiştir.

4. Geģerlik ve güvenirlik sağlama: Bir çalısmanın geçerlik ve güvenilirlik niteliği, çalışmanın bilimsel ve kabul edilebilirliği önemlidir. Nitel araştırmada geçerlik, araștırma bulguların doğruluğu; güvenilirlik ise tekrarlanabilirlik esasına dayanır (Yıldırım ve Şimşek, 2011: 255). Oluşturulan temalar araştırma grubunun dışında, alanında uzman dört akademisyene birbirlerinden habersiz olarak inceletilmiş ve ifadelerde bir iki düzeltme ile uygunluğuna dair onayları alınmıştır.

5. Veri kayde ve yorumlama: Çalışmadan elde edilen verilerin çözümlenmesinde içerik analizi tekniği kullanılmıştır. İçerik analizinde, birbirine benzeyen verileri belirli kavramlar, temalar çerçevesinde bir araya getirilir ve bunlar okuyucunun anlayabileceği bir biçimde organize edilerek yorumlanır (Yıldırım ve Şimşek, 2005: 227). 


\section{Bulgular}

Araştırmanın bulgularına göre, katılımcıların bazı maddelerde doldurmaları gereken boşluklara metafor bulamadığı veya metafor bulsa bile nedenini açıklayamadığı durumlar olduğu belirlenmiştir. Çalışmada, her madde bağımsız düşünüldüğünden dolayı geçersiz cevaplar sadece madde olarak elenmiş, uygun şekilde kullanılan ve açıklanan diğer maddeler çalışmaya dâhil edilmiştir. Çalışma kapsamında katılımcılar tarafindan oluşturulan metaforlar kullanım sıklığına bakılarak (en az 3 kişinin oluşturduğu) tablolarda gösterilmiştir.

1. Sosyal ağlarla ilgili oluşturulan metaforlar, olumlu-olumsuz ve soyut-somut ayrımına göre hangi temalarda yer almaktadır?

Söz konusu örnekler üzerinden (facebook, twitter, instagram vs.) sosyal paylaşım ağlarıyla ilgili cümleler incelendiğinde katılımcıların yarıdan fazlasının; kullanmıyorum, vardı ama kapattım, vazgeçtim, yok gibi açıklamalar yaptığı görülmüştür (Tablo 2). Özellikle temel grubu oluşturanlarda, ailelerin çocukları koruma amaçlı söz konusu uygulamaları kötülemeleri ve yasaklamalarına bağlı olarak olumsuz algının yaygınlaştığ1 söylenebilir. Üst grubu oluşturan bireylerin ise sosyal paylaşım ağlarındaki şahıs ve konuları kanıksadığ1 ve paylaşımlardan sıkılarak olumsuz algının arttığı anlaşılmaktadır. Ancak orta grubu oluşturan bireylerin, kendini özgürce ifade edebilme ortamı ihtiyacını söz konusu sosyal ağlarla karşıladığ1 ve paylaşımda bulunduğu belirlenmiştir.

Örnek:

TK32: Sosyal paylaşım ağlar benim için bataklık gibidir çünkü oraya girersen çıamaæsın.

TK50: Sosyal paylaşım ağlar benim için ağzım gibidir çünkü hep oradan konusuyorum.

OK2: Sosyal paylaşım ağları benim için altın günü gibidir şünkü tüm tanıdıklarm oradadır.

OK52: Sosyal paylaşım ağlar benim için özel dünyam gibidir çünkü orada özgürüm ve kendimim.

ÜK13: Sosyal paylaşım ağlar benim için çöp torbası gibidir çünkü herkes içine kendi saçmaliğgm atar. bağlanir.

ÜK37: Sosyal paylaşım ağlar benim için mabkeme salonu gibidir çünkü her konu konuşulup tartşsllir ve karara

Tablo 2. Sosyal Ağlarla İlgili (facebook, twitter, instagram vs.) Oluşturulan Metaforlarn Dağzlım Soyut Somut Gelecek

\begin{tabular}{|c|c|c|c|}
\hline & Temalar & & En sik kullanılan metaforlar \\
\hline & Paylaşma & $\begin{array}{l}\text { Somut } \\
\text { Soyut }\end{array}$ & $\begin{array}{l}\text { arkadaşlarla buluştuğum kafe, ağzım, parkta bank, damarlarım, haber tv, altın günü, } \\
\text { özgürlük, hayat, günlüğümdeki anılarım, }\end{array}$ \\
\hline Olumlu & $\begin{array}{l}\text { Haber } \\
\text { alma } \\
\text { Eğlence }\end{array}$ & $\begin{array}{l}\text { Somut } \\
\text { Soyut } \\
\text { Somut } \\
\text { Soyut }\end{array}$ & $\begin{array}{l}\text { banka, postac1, güvercin, gazetem, } \\
\text { hayat bağım, } \\
\text { lunapark, oyuncağım, } \\
\text { özel alanım, kendi dünyam, }\end{array}$ \\
\hline Olumsuz & $\begin{array}{l}\text { Zaman } \\
\text { kayb1 } \\
\text { Bilgi } \\
\text { kirliliği }\end{array}$ & $\begin{array}{l}\text { Somut } \\
\text { Soyut } \\
\text { Somut } \\
\text { Soyut }\end{array}$ & $\begin{array}{l}\text { masa süsü, kahvehane, katalog, yarış alanı, } \\
\text { gereksiz, hırsı, } \\
\text { çöplük, çöp torbası, bataklık, mahkeme salonu, tozlu depo, } \\
\text { dedikodu kazanı, }\end{array}$ \\
\hline
\end{tabular}

2. İnternet bağlantısıyla ilgili oluşturulan metaforlar, olumlu-olumsuz ve soyut-somut ayrımına göre hangi temalarda yer almaktadır?

Tablo 3’te görüldügü üzere, katıllımcılar sosyal paylaşım ağlarına karşı genellikle temkinli yaklaşırken internet ile ilgili algiların hemen hemen tamamına yakınını olumlu olması hatta temel ihtiyaç gibi algılanması ilginçtir. İnternet bağlantısı olmamasını, yaşamak için gerekli olan can damarları kesilmiş gibi hayati bir sorun olarak algiladığı görülmektedir. Ayrıca bireyde dünyayla ve çevreyle bağlantılarının tamamen koptuğu endişesinin geliştiği ve yalnızlaşarak kendini kötü hissettiği belirlenmiştir. Bu bağlamda bireylerin internet bağlantısını hayatta kalabilmek için teknolojik ve suni üretilmiş bir "göbek bağı" olarak gördüğ̈̈ söylenebilir.

Örnek:

TK12: Internet benim için kardeşim gibidir çünkü onsu乏yalmz kalrm.

TK57: Internet benim için cankurtaran gibidir çünkü onsuz ödev yapamam, oyun oynayamam.

TK13: Internet bağlantım olmadiğgnda kendimi serbest hissediyorum çünkü futbol oynayabiliyorum. 
TK49: Internet bă̆lantım olmadiğında kendimi süte ibtiyacı olan yavru kedi gibi hissediyorum çünkü mutsuz. oluyorum.

OK5: Internet benim için su gibidir çünkü onsuzyaşayamam.

OK17: Internet benim için săg kolum gibidir çünkü her zaman onu kullanırm.

OK28: Internet bağlantım olmadığında kendimi buzurlu bissediyorum çünkü sürekli elime alıp bir seyler yapmak zorunda kalmiyorum.

OK86: Internet bağlantım olmadĭ̆gnda kendimi ölmüş hissediyorum çünkü yapacak hiçbir şeyim kalmıyor.

ÜK17: Internet benim için çocuğum gibidir çünkü o benim vazgeçemediğim aynlmazparçam.

ÜK45: Internet benim için kalbim gibidir çünkü o wifi bağlantısı arttıkça benim de hayata bağlantım artıyor.

ÜK39: Internet bă̆lantım olmadığında kendimi cabil hissediyorum çünkü haberlerden, olaylardan, arkadaşlardan habersiz kaliyorum.

ÜK32: Internet bă̆lantım olmadiğında kendimi bornoz cebi gibi hissediyorum çünkü biçbir işe yaramaz, sadece vardir.

Tablo 3. Internetle İgili Olușturulan Metaforlarn Dağglmm Soyut Somut

\begin{tabular}{|c|c|c|c|}
\hline & Temalar & & En sik kullanilan metaforlar \\
\hline \multirow[t]{2}{*}{ Olumlu } & $\begin{array}{l}\text { Temel } \\
\text { ihtiyaç } \\
\text { Eğitim } \\
\text { arac1 } \\
\text { Eğlence } \\
\text { kaynağ1 }\end{array}$ & $\begin{array}{l}\text { Somut } \\
\text { Soyut } \\
\text { Somut } \\
\text { Soyut } \\
\text { Somut } \\
\text { Soyut }\end{array}$ & $\begin{array}{l}\text { evim, kardeşim, suyum, sağ kolum, güneşim, sabah kahvem, bir organım, çocuğum, } \\
\text { elim ayağım, , beynim, , ailem, kankim, } \\
\text { yüreğim, ,canım, hayatım, her şeyim, dünyam, süper kahramanım, } \\
\text { kitabım, kütüphanem, bilgili amcam, sanal yardımcım, } \\
\text { yol göstericim, hayat kılavuzum, } \\
\text { cankurtaranım, pencerem, çikolata, dostum, } \\
\text { sıkıntı savarım, özgürlüğüm, }\end{array}$ \\
\hline & $\begin{array}{l}\text { Bağlant1 } \\
\text { arac1 }\end{array}$ & $\begin{array}{l}\text { Somut } \\
\text { Soyut }\end{array}$ & $\begin{array}{l}\text { ip, köprü, } \\
\text { hayatla bağım, }\end{array}$ \\
\hline \multirow[t]{2}{*}{ Olumsuz } & $\begin{array}{l}\text { İhtiyaç } \\
\text { fazlas1 } \\
\text { Endişe } \\
\text { kaynağ1 }\end{array}$ & $\begin{array}{l}\text { Somut } \\
\text { Soyut } \\
\text { Somut } \\
\text { Soyut } \\
\end{array}$ & $\begin{array}{l}\text { kötü arkadaşım, } \\
\text { hiçbir şey, } \\
\text { derin deniz, } \\
\text { bağımlılığım, }\end{array}$ \\
\hline & & & İnternet bağlantısı olmadığında; \\
\hline Olumlu & & $\begin{array}{l}\text { Somut } \\
\text { Soyut }\end{array}$ & $\begin{array}{l}\text { kuş, } \\
\text { aynı, her zamanki gibi, iyi, mutlu, özgür, normal, rahatlamış, masum, süper, huzurlu }\end{array}$ \\
\hline Olumsuz & & Somut & $\begin{array}{l}\text { Ölmüş, hücrede, bornoz cebi, arada sıkışmış, elsiz bir insan, boğulmuş, yakıtı bitmiş } \\
\text { araba, trafikte sıkışmıs Ferrari, hasta, kafesteki kuş, doğal gazsız ev, çplak, ameliyata } \\
\text { alınmış hasta, evsiz, beyinsiz, boş, } \\
\text { oyuncağı olmayan çocuk, kötü, mutsuz, sinirli, yalnız, garip, fakir, cahil, berbat, çaresiz, } \\
\text { bir hiç, kaybolmuş, eksik, terkedilmiş, deli, }\end{array}$ \\
\hline
\end{tabular}

3. Akıllı telefonlarla ilgili oluşturulan metaforlar, olumlu-olumsuz ve soyut-somut ayrımına göre hangi temalarda yer almaktadır?

Katılımcıların yarıya yakınının akıllı telefonları bağlantı kurmak ve eğlenmek için ihtiyaç olarak algıladığı anlaşılmaktadır (Tablo 4). Ancak söz konusu araçların yarattığı bağımlılık inkâr edilemeyecek seviyededir. Telefonları yanlarında olmadığı zaman kendilerini ölü, yetim, öksüz gibi algıladıkları ve mutsuz, güvensiz hissettikleri belirlenmiştir. Bu bağlamda cep telefonları ile bedensel bir bütünleşiklik hissi geliştirdikleri söylenebilir. Bu da son derece sakıncalı bir bağımlılığı işaret etmektedir.

Örnek:

TK20: Telefonum benim için oksijen gibidir çünkü onsu乏 yasayamam.

TK71: Telefonum benim için lunapark gibidir çünkü onunla iyi vakit geçirir, eğlenirim.

OK36: Telefonum benim için bedenim gibidir çünkü iletişim aracumdrr.

OK68: Telefonum benim için sol kolum gibidir çünkü her zaman yanmmdadır.

ÜK20: Telefonum benim için kimliğim gibidir çünkü asla yanmmdan ayırmam. 
ÜK58: Telefonum benim için elim ayağım gibidir çünkü onsuzyapamam hep yanımdadır.

TK6: Telefonum olmadı̆̆ında kendimi özgür bir hayvan gibi hissediyorum çünkü yanımda olunca hep ona bakıyorum.

TK78: Telefonum olmadiğında kendimi ölü gibi bissediyorum çünkü yapacak biçbir şey yoktur.

OK27: Telefonum olmadiğında kendimi rahat gibi hissediyorum çünkü ulaşamama sorunu yok.

OK43: Telefonum olmadiğında kendimi yapayalnı gibi hissediyorum çünkü konuşamıyorum, soyutlanmış oluyorum.

ÜK8: Telefonum olmadiğında kendimi eksik gibi hissediyorum çünkü her an elimde olmal.

ÜK31: Telefonum olmadığında kendimi çölde susuz gibi hissediyorum çünkü nefes alamıyorum.

Tablo 4. Akellh Telefonlarla Ilgili Olusturulan Metaforların Dağglamı

\begin{tabular}{|c|c|c|c|}
\hline & Temalar & & En sik kullanilan metaforlar \\
\hline \multirow{4}{*}{ Olumlu } & Araç & $\begin{array}{l}\text { Somut } \\
\text { Soyut }\end{array}$ & $\begin{array}{l}\text { çantam, cankurtaran, bedenim, } \\
\text { taşınabilir hayat kaynağım, }\end{array}$ \\
\hline & İhtiyaç & $\begin{array}{l}\text { Somut } \\
\text { Soyut }\end{array}$ & $\begin{array}{l}\text { su, arkadaş, elim ayağım, parçam, yemeğim, sevgilim, besin kaynağı, } \\
\text { oksijen, her şeyim, hayatım, vazgeçilmezim, yoldaş, }\end{array}$ \\
\hline & Eğlence & $\begin{array}{l}\text { Somut } \\
\text { Soyut }\end{array}$ & $\begin{array}{l}\text { lunapark, oyun parkım, oyuncağım, aksesuarım, } \\
\text { gizli dünyam, oyun kaynağım, sihirli kale, }\end{array}$ \\
\hline & Bağlantı & $\begin{array}{l}\text { Somut } \\
\text { Soyut }\end{array}$ & $\begin{array}{l}\text { yardımcım, dostum, ailem, elim, köprü, } \\
\text { hayat, }\end{array}$ \\
\hline \multirow[b]{2}{*}{ Olumsuz } & Bağımlılık & $\begin{array}{l}\text { Somut } \\
\text { Soyut }\end{array}$ & $\begin{array}{l}\text { hapishanem, kelepçe, } \\
\text { eziyet, içim, her şeyim, }\end{array}$ \\
\hline & Fazlalık & $\begin{array}{l}\text { Somut } \\
\text { Soyut }\end{array}$ & $\begin{array}{l}\text { bilekliğim, } \\
\text { hırsız, gereksiz bir şey, hiçbir şey, }\end{array}$ \\
\hline \multicolumn{4}{|c|}{ Telefon olmadığında; } \\
\hline Olumlu & & $\begin{array}{l}\text { Somut } \\
\text { Soyut }\end{array}$ & $\begin{array}{l}\text { tekrar insan, özgür bir hayvan, } \\
\text { rahat, normal, özgür, özel, serbest, }\end{array}$ \\
\hline Olumsuz & & Somut & $\begin{array}{l}\text { hasta, çölde susuz, kuyuya düşmüş, aç kalmış, karanlıkta kalmış, teki kaybolmuş } \\
\text { çorap, çılak, evsiz, yetim, öksüz, sap, oruçlu, silahsız, çürük elma, ölü, soyulmuş, } \\
\text { beyinsiz, } \\
\text { eksik, kötü, mutsuz, boşlukta, çaresiz, yalnız, yarım, boş, soyutlanmış, geri kalmış, } \\
\text { güvensiz, aptal, }\end{array}$ \\
\hline
\end{tabular}

4. Oluşturulan metaforların olumlu veya olumsuz olması gruplara göre farklılık göstermekte midir?

Oluşturulan metaforların olumlu veya olumsuz olmasının gruplara göre farklılıkları Tablo 5'te görülmektedir.

Tablo 5. Olumlu ve Olumsuz. Anlamlı Metaforlarn Gruplara Göre Dăğlımı

\begin{tabular}{llccc}
\hline & & Temel & Orta & Üst \\
\hline 1. Sosyal paylaşım ağlar1 & Olumlu & $28(37.34 \%)$ & $63(73.25 \%)$ & $28(46.67 \%)$ \\
(T:75 O:86 Ü:60) & Olumsuz & $47(62.66 \%)$ & $23(26.75 \%)$ & $32(53.33 \%)$ \\
\hline 2. İnternet & Olumlu & $79(95.18 \%)$ & $90(91.84 \%)$ & $65(95.58 \%)$ \\
(T:83 O:98 Ü:68) & Olumsuz & $4(4.82 \%)$ & $8(8.16 \%)$ & $3(4.42 \%)$ \\
\hline 3. İnternet bağlantisının olmamas1 & Olumlu & $11(13.75 \%)$ & $9(9.10 \%)$ & $2(2.99 \%)$ \\
(T:80 O:99 Ü:67) & Olumsuz & $69(86.25 \%)$ & $90(90.90 \%)$ & $65(97.01 \%)$ \\
\hline 4. Akıllı telefon & Olumlu & $25(36.76 \%)$ & $83(83.00 \%)$ & $59(90.76 \%)$ \\
(T:68 O:100 Ü:65) & Olumsuz & $43(63.24 \%)$ & $17(17.00 \%)$ & $6(9.24 \%)$ \\
\hline 5. Ak1llı telefonun yaninda olmamas1 & Olumlu & $36(57.14 \%)$ & $11(11.11 \%)$ & $5(8.07 \%)$ \\
(T:63 O:99 Ü:62) & Olumsuz & $27(42.86 \%)$ & $88(88.89 \%)$ & $57(91.93 \%)$ \\
\hline
\end{tabular}

Tablo 5 incelendiğinde, sosyal paylaşım ağlarıyla ilgili cümlelerdeki metaforlardan toplam 254 katılımcının 85'ini oluşturan temel gruptan 75 tanesinin, 101'ini oluşturan orta gruptan 86 tanesinin, 68'ini oluşturan üst gruptan ise 60 tanesinin geçerli sayıldığ1 görülmektedir. Sosyal paylaşım ağlarıyla ilgili en fazla olumlu metaforu orta grubu oluşturan bireyler üretirken, olumsuz metaforları temel grubu oluşturan bireyler üretmiştir.

Internetle ilgili cümlelerdeki metaforlardan toplam 254 katılımcının 85'ini oluşturan temel gruptan 83 tanesinin, 101'ini oluşturan orta gruptan 98 tanesinin, 68’ini oluşturan üst gruptan ise 68 tanesinin geçerli 
sayıldığı görülmektedir. İnternet bağlantısıyla ilgili en fazla olumlu metaforu üst grubu oluşturan bireyler üretirken, olumsuz metaforları orta grubu oluşturan bireyler üretmiştir.

İnternet bağlantısının olmamasıyla ilgili cümlelerdeki metaforlardan toplam 254 katılımcının 85 'ini oluşturan temel gruptan 80 tanesinin, 101'ini oluşturan orta gruptan 99 tanesinin, 68'ini oluşturan üst gruptan ise 67 tanesinin geçerli sayıldığı görülmektedir. İnternet bağlantısının olmamasıyla ilgili en fazla olumlu metaforu temel grubu oluşturan bireyler üretirken, olumsuz metaforları üst grubu oluşturan bireyler üretmiştir.

Akıllı telefonlarla ilgili cümlelerdeki metaforlardan toplam 254 katıllımcının 85 'ini oluşturan temel gruptan 68 tanesinin, 101'ini oluşturan orta gruptan 100 tanesinin, 68'ini oluşturan üst gruptan ise 65 tanesinin geçerli sayıldı̆̆1 görülmektedir. Akıllı telefonlarla ilgili en fazla olumlu metaforu üst grubu oluşturan bireyler üretirken, olumsuz metaforları temel grubu oluşturan bireyler üretmiştir.

Akıllı telefonun yanında olmamasıyla ilgili cümlelerdeki metaforlardan toplam 254 katılımcinın 85'ini oluşturan temel gruptan 63 tanesinin, 101'ini oluşturan orta gruptan 99 tanesinin, 68'ini oluşturan üst gruptan ise 62 tanesinin geçerli sayıldığı görülmektedir. Akıllı telefonun yanında olmamasıyla ilgili en fazla olumlu metaforu temel grubu oluşturan bireyler üretirken, olumsuz metaforları üst grubu oluşturan bireyler üretmiştir.

\section{Tartışma, Sonuç ve Öneriler}

Metaforun temel özelliği, yeni bir kavram karşısında bireyin kendi yaşamı ile ilişki kurarak metaforlarını oluşturmasıdır. Bu noktada geçmişe yüklenen anlamlar büyük önem arz etmekte ve geleceği etkilemektedir. Bu çalışmanın amacı, bireylerin internet, sosyal dünya ve akıllı telefonlara ilişkin algılarını metaforlar aracıllğıyla belirlemektir. Zira bu algılar teknolojinin bireyin hayatına yansımasının ipuçlarını verecektir.

Bu bağlamda, gerçekleştirilen çalışmada katılımcıların sosyal ağlarla ilgi oluşturdukları metaforların daha çok olumlu ve somut metaforlar olduğu belirlenmiştir. Oysa metropol insanlarının yaşam tarzları içerisinde kendilerine vazgeçilmez bir yer bulan bu ağların, üzerinde uzlaşılmış sosyalleşme tanım ve tanılarına uyup uymadığı; dahası toplumsal hayata kattıkları ve toplumsal hayattan götürdükleri büyük bir soru işaretidir (Dilmen ve Öğüt, 2010, s. 237). Yusufoğlu (2017) da yaptığı araştırmada 380 katılımcıdan \% 59,3'ünün telefonla sesli iletişimden sonra akıllı telefonların en önemli fonksiyonunun sosyal paylaşım araçları olarak görüldügünü belirlemiştir. Bu çalışmada sosyal paylaşım ağlarıyla ilgili en fazla olumlu metaforu orta grubu oluşturan bireylerin ürettiği görülürken olumsuz metaforları temel grubu oluşturan bireylerin ürettiği belirlenmiştir. Bu sonuca göre, özellikle temel grubu oluşturan çoğu katılımcının sosyal paylaşım ağlarının kötüye kullanım olasıllğındaki artışla ilgili uyarılardan etkilendiği söylenebilir. Zira gerçek hayatta mevcut olan güvenlik ve gizlilikle ilgili risklerin çoğunun internet alanına taşındığı; bu risklerin de internette mevcut olan risklerle birleştiği bir gerçektir (Aslanyürek, 2016, s. 85). Olumlu metafor üretimiyle ilgili üst gruptaki katılımcı sonuçları ise paylaşım ağlarındaki cazip etkinin kanıksanmışlık ve doymuşluk duygularıyla azalmaya başladığı şeklinde yorumlanabilir. Ancak söz konusu uygulamaları en yoğun kullanan ve hayatının önemli bir parçası olarak gören bireylerin daha çok ergenlik dönemindeki orta grubu oluşturan katıllımcilar olduğu anlaşılmıştır.

İnternet bağlantısıyla ilgili oluşturulan metaforlar incelendiğinde de olumlu ve somut metaforların yer aldığı belirlenmiştir. İnternet bağlantısıyla ilgili en fazla olumlu metaforu üst grubu oluşturan bireyler üretirken, olumsuz metaforları orta grubu oluşturan bireyler üretmiştir. Ancak teknolojinin sınırları kaldırmasıyla birlikte internet bağlantısının hayatın temel ihtiyaçları arasına girdiği algısının oluştuğu anlaşılmaktadır. İnternet bağlantısının tüm yaş grupları için taşıdığı önem ve hayatilik algısı, oluşturulan metaforlardan belirgin olarak görülmektedir. Ancak internetin hayatımıza girişiyle sanalizm çağı başlamış ve bu çağ kendi hastalığını da yaratmıştır: "İnternet bağımlllı̆̆’" (Ögel, 2012, s. 4). İnternet bağlantısının olmamasiyla ilgili en fazla olumlu metaforu temel grubu oluşturan bireyler üretirken, olumsuz metaforları üst grubu oluşturan bireyler üretmiştir. İnternet bağlantısının kesilmesinin adeta hayatla göbek bağ1 kesilmişlik duygusu yarattı̆̆ının belirtilmesi dikkat çekicidir. Aslanyürek (2016) internetle ilgili yaptı̆̆ bir araştırmada toplam 479 katılımcının \% 89'unun interneti bilgi almak, \% 78'inin iletişim kurmak, \% 75'inin ise eğlence amacıyla kullandığını ve \% 68'inin internet aracıllğı ile bazen alışveriş yaptıklarını, \% 80'inin ise bankacılık işlemlerini internet aracıllı̆̆yla gerçekleştirdiği sonucuna ulaşmıştır. Teknoloji alanında önemli 
gelişmeler yaşanmış ve sosyal ağların da hayatımıza girmesiyle birlikte internet kullanımı çok yüksek oranlara ulaşmıştır.

Ak1llı telefonlarla ilgili oluşturulan metaforlar incelendiğinde ise, yoğun olarak olumlu metaforlar üretilmesine karşın somut anlamda üretilen metaforlara yaklaşık oranda soyut anlamda metaforların da üretildiği anlaşılmışır. Bu bağlamda, kattlımcıların akıllı telefonlarına duygusal boyutta yaklaştı̆̆1 söylenebilir. Giderek bireyselleşen modern yaşamda her insan sahip olduğu telefon ile daha fazla özgürleşmiş ve bununla kendisine yeni bir kimlik yaratmıstır (Yusufoğlu, 2017, s. 2417). Ancak bu durum bağımlılık yaratan bir çılgınlık hâlini aldığı görülmektedir. İnternete bağlı akıllı telefonların ortaya çıkmasıyla "nomofobi" denilen bir başka teknolojiden dolayı ortaya çıkan sendrom yayılmaya başlamıştır (Gezgin, Şumuer, Arslan ve Yıldırım, 2017; Gezgin, Çakır ve Yıldırım, 2018). Nomofobi tüm bireylerde de gelişebilmesi rağmen özellikle genç nesil arasında yaygınlaşmaktadır (Gezgin, 2017). Kişilerin mobil cihazlara olan bağımlılığının bir sonucu olduğu düşünülen nomofobi; mobil cihazlardan uzak kalındığında kişide sinir, stres veya agresif tavırlar gibi etkilerle belli olabilmektedir (Polat, 2017, s. 171). Bu da demektir ki modern çağın bir aracı olan akıllı telefonlar, bireyleri kendilerine bağlamakta, alıştırmakta ve bireyler artık isteseler de bu durumdan kurtulamamaktadırlar (Yusufoğlu, 2017, s. 2432). İnternete bağlı akıllı telefonları yanında olmayan bireylerin hissettikleri kaygyyla ürettikleri metaforlar endişe verici düzeydedir. Ak1llı telefonlarla ilgili en fazla olumlu metaforu üst grubu oluşturan bireyler üretirken, olumsuz metaforları temel grubu oluşturan bireyler üretmiştir. Ancak yine de sosyal paylaşım ağlarıyla ilgili olumsuz alg1 artsa da akıllı telefonlara bağımlılıkta temel gruptaki katılımcılar da dâhil hiçbir azalma olmadığı anlaşılmıştır.

Teknolojik aletlerle kaydedilerek dünyaya gözlerini açan jenerasyonun teknolojiyi bu derece içselleştirmesi kaçınılmazdır. Bu, pek de insani sayılamayacak yoğun teknoloji kullanımına tepki oluşumu gecikmemiş ve bağımlılık yapan diğer maddeler için olduğu gibi bu alanda da toplumsal farkındalığın arttırllmasına yönelik talep doğmuştur (Ertemel, Aydın, 2018, s. 682). Bu bağlamda günümüzde teknolojiye daha temkinli yaklaşan ve çocuklarını korumaya çalışan bir ebeveyn kitlesi oluştuğu söylenebilir. Gerçekleştirilen çalışmanın sonuçları da sosyal paylaşım ağları, internet ve akıllı telefonlarla ilgili oluşturulan metaforlar incelendiğinde, en yoğun olumsuz metafor üreten grubun temel grup olması bu tedbirlerin çocuklara yansıması olarak yorumlanabilir. Olumlu anlamda en yoğun metafor üreten grubun ise orta grup olduğu belirlenmiştir. Bu gruptaki katılımcılar yaşları gereği kendini tanıma, kişiliğini oluşturma ve çevreye birey olarak kendini kabul ettirme dönemindeki çocuklar olduğu için ebeveynlerin onları teknolojiden uzaklaştırma çabaları karşısında tepkisel olarak teknolojiye daha da bağlanmalarına neden olabilmektedir. Üst düzey katılımclarda kendini hissettiren bilinçli farkındalığın henüz orta grup katılımcılarda olgunlaşmadığı düşünülebilir. Yeşilay kurumsal web sayfasında bağımlılıkları şu başlıklarla gruplandırmıştır: Sigara ve tütün bağımlılığı, Alkol bağımlılığ1, Madde bağımlılığı, Teknoloji bağımlılığ1 ve Kumar bağımlılı̆ğ (https://www.yesilay.org.tr). Bağımllık ciddi bir hastalıktır.

\section{Kaynakça}

Ada, S. ve Tatlı, H. S. (2013). Akıllı telefon kullanımını etkileyen faktörler üzerine bir araştırma. Online: http://ab.org.tr/ab13/bildiri/74.pdf, 10.04.2015

Aktekin, Ç. N. (2013). İngilizce öğretmenlerinin ve yabancı dil öğrenen öğrencilerin tutum ve inançlarının metafor yoluyla ortaya çıkarılması. Uludağ Üniversitesi Eğitim Fakültesi Dergisi 26(2), 405-422.

Altıntaş, G., Kahraman, E., Ülger, E. ve Altıntaş, U. S. (2014). Fen ve teknoloji dersi 'maddenin tanecikli yapısı' ünitesi kavramları üzerine öğrencilerin geliştirdikleri metaforlar. Eğitim ve Öğretim Arastırmalar Dergisi, 3(3), 271282.

Arslan, M. M. ve Bayrakçı, M. (2006). Metaforik düşünme ve öğrenme yaklaşımının eğitim-öğretim açısından incelenmesi. Millí Ë̈itim, 35(171), 100-108.

Aslanyürek, M. (2016). İnternet ve sosyal medya kullanıcılarının internet güvenliği ve çevrimiçi gizlilik ile ilgili kanaatleri ve farkındalıkları. Maltepe Üniversitesi İletişim Fakültesi Dergisi, 3(1), 80-106.

Berson, I. ve Berson, M. (2003). Digital literacy for effective citizenship. Social Education, 67(3), 164- 167

Çelikten, M. (2005). Kültür ve öğretmen metaforlar1. Sosyal Bilimler Enstitüsü Dergisi, 21(2), 269-283.

Ceran, D. (2015). Türkçe öğretmeni adaylarının Türkçe ders kitaplarına ilişkin metaforları, Uşak Üniversitesi Sosyal Bilimler Dergisi, 8(3), 121-140.

Chen, B. ve Denoyelles, A. (2013). Exploring students' mobile learning practices in higher education. Educause Review. Retrieved from http://www. educause. edu/ero/article/exploring-students-mobile-learning-practiceshigher-education.

Coogan, K. ve Kangas, S. (2001). Nuoret ja kommunikaatioakrobatia, 16-18-vuotiaiden nuorten k. annykk. a- ja internetkulttuurit. Nuorisotutkimusverkosto ja Elisa ommunications. Elisa tutkimuskeskus. Raportti 158. 
Demirci, K., Orhan, H., Demirdas, A., Akpinar, A. ve Sert, H. (2014). Validity and reliability of the Turkish version of the smartphone addiction scale in a younger population. Klinik Psikofarmakoloji Bülteni (Bulletin of Clinical Psychopharmacology), 24(3), 226-34.

Denzin, N. K. ve Lincoln, Y. S. (2011). The SAGE handbook of qualitative research. USA: SAGE Publications Inc.

Dilmen, N. E. ve Ögüt S. (2006). Yeni iletișim ortamları ve etkileșime iletişimsel bilișim yaklașımı. Yeni Illetișim Ortamlar ve Etkileşim Uluslararası Konferansi, İstanbul.

Dilmen, E. ve Öğ̈̈, S. (2010). Sosyalleşmenin yeni yüzü: sosyal paylaşım ağları. M.Ü. Yeni Medya ve Etkileşim Konferansı Bildiri Kitabı. ss. 237-242.

Erdem, S. (2010). Atasözlerinde metaforların işleyişi. Milli Folklor, 22(88), 33-37.

Ertemel, A. V. ve Aydın, G. (2018). Dijital ekonomide teknoloji bağımlilı̆̆1 ve çözüm önerileri. Addicta: The Turkish Journal on Addictions 5(4), 665-690.

Gezgin, D. M. (2017). Exploring the influence of the patterns of mobile internet use on university students' nomophobia levels. European Journal of Education Studies, 3(6), 29-52.

Gezgin, D. M. (2018). Understanding patterns for smartphone addiction: Age, sleep duration, social network use and fear of missing out. Cypriot Journal of Educational Sciences, 13(2), 409-421.

Gezgin, D. M., Cakir, O. ve Yildirim, S. (2018). The relationship between levels of nomophobia Prevalence and Internet addiction among High School Students: The factors influencing nomophobia. International Journal of Research in Education and Science, 4(1), 215-225.

Gezgin, D. M., Hamutoğlu N. B., Samur, Y. ve Yıldırım, S.(2018). Genç nesil arasında yaygınlaşan bir bağımlılık: akıllı telefon bağımlılığının farklı değişkenler açısından incelenmesi. Eğitim Teknolojisi Kuram ve Uygulama, 8(2), 212-231.

Gezgin, D. M., Şumuer, E., Arslan, O. ve Yıldırım, S. (2017). Nomophobia prevalence among pre-service teachers: A case of Trakya University. Trakya Üniversitesi Eğitim Fakültesi Dergisi, 7(1).

Judd, T. (2014). Making sense of multitasking: The role of Facebook. Computers \& Education, 70, 194-202.

Karaaslan, İ. A. ve Budak, L. (2012). Üniversite öğrencilerinin cep telefonu özelliklerini kullanımlarının ve gündelik iletişimlerine etkisinin araştırılması. Journal of Yasar University, 26(7), 4548-4525.

Karaçanta, H. (2013). Üniversite öğrencilerinin milli değerlere yönelik metaforları. Gą̧i Üniversitesi Endüstriyel Sanatlar Ë̆itim Fakültesi Dergisi, 32, 107-114.

Karpinski, A. C., Kirschner, P. A., Ozer, I., Mellott, J. A. ve Ochwo, P. (2013). An exploration of social networking site use, multitasking, and academic performance among United States and European university students. Computers in Human Behavior, 29(3), 1182-1192.

Kaya, M. F.(2014). Sosyal bilgiler öğretmen adaylarının çevre sorunlarına ilişkin algıları: metafor analizi örneği. Turkish Studies, 9(2), 917-931.

Kibona, L. ve Mgaya, G. (2015). Smartphones' effects on academic performance of higher learning students. Journal of Multidisciplinary Engineering Science and Technology, 2(4), 777-784.

King, A. L. S., Valença, A. M., Silva, A. C., Sancassiani, F., Machado, S. ve Nardi, A. E. (2014). "Nomophobia": Impact of cell phone use interfering with symptoms and emotions of individuals with panic disorder compared with a control group. Clinical Practice and Epidemiology in Mental Health, 10, 28-35.

Ko, C. H., Yen, J. Y., Yen, C. F., Chen, C. S. ve Chen, C. C. (2012). The association between Internet addiction and psychiatric disorder: a review of the literature. European Psychiatry, 27(1), 1-8.

Kwon, M., Kim, D. J., Cho, H. ve Yang, S. (2013). The smartphone addiction scale: development and validation of a short version for adolescents. PloS one, 8(12), e83558.

Mertol, H., Doğdu, M. ve Yılar, B. (2013). Üstün zekâlı ve yetenekli öğrencilerin sosyal bilgiler dersine ilişkin metaforik algiları. Üstün Yetenekli Eğitimi Arasttrmalar Dergisi, 1(3), 176-183.

Mete, F. ve Ayranc1, B. B. (2016). Dil ve edebiyata ilişkin algiların metaforlar yoluyla incelenmesi. Dede Korkut Uluslararası Türk Dili ve Araștırmalar Dergisi, 5(11), 53-64.

Morgan, G. (1998). Yönetim ve örgüt teorilerinde metafor (Çev: G. Bulut). İstanbul: BZD Yarıncilık.

Noyan, C. O., Enez-Darçın, A., Nurmedov, S., Yılmaz, O. ve Dilbaz, N. (2015). Akıllı telefon bağımlılı̆̆ı ölçeğinin kısa formunun üniversite öğrencilerinde Türkçe geçerlilik ve güvenilirlik çalışması. Anadolu Psikiyatri Dergisi, 16, 73-81.

Ögel, K. (2012). Internet bağımlıl̆ğ. İstanbul: Kültür Yayınları.

Özbaş, B. Ç. ve Aktekin, S. (2013).Tarih öğretmen adaylarının tarih öğretmenliğine ilişkin inançlarının metafor analizi yoluyla incelenmesi. Ë̆itimde Kuram ve Uygulama, 9(3), 211-228.

Özbek, V., Alnıaçık, Ü., Koç, F., Akkılıç, M. E. ve Kaş, E. (2014). Kişilik özelliklerinin teknoloji kabulü üzerindeki doğrudan ve dolaylı etkileri: Akıllı telefon teknolojileri üzerine bir araştırma. International Review of Economics and Management, 2(1), 36-57.

Özdemir S. ve Akkaya E. (2013). Genel lise öğrenci ve öğretmenlerinin okul ve ideal okul algılarının metafor yoluyla analizi. Kuram ve Uygulamada Eğitim Yönetimi, 19(2), 295-322.

Polat, R. (2017). Dijital hastalik olarak nomofobi. Yeni Medya Elektronik Dergi-eJNM, 1(2), 164-172.

Rosen, L. D., Carrier, L. M. ve Cheever, N. A. (2013). Facebook and texting made me do it: Mediainduced taskswitching while studying. Computers in Human Behavior, 29(3), 948-958. 
Samaha, M. ve Hawi, N. S. (2016). Relationships among smartphone addiction, stress, academic performance, and satisfaction with life. Computers in Human Behavior, 57, 321-325.

Şar, A. H. (2013). Examination of lonelinessand mobil phoneaddiction problem observed in teenagersfromthesomevariables. The Journal of Academic Social Science Studies International Journal of Social Science, 6(2), 1207-1220.

Şar, A. H. ve Işıklar, A. (2012). Problemli mobil telefon kullanım ölçeğinin Türkçeye uyarlaması. International Journal of Human Sciences [Online], 9(2), 264-275.

Sarrab M. (2015). Mobile Learning (m-learning) Concepts, Characteristics, Methods, Components: Platforms and Frameworks. 2015.

Sevim, O., Veyis, F. ve Kınay, N. (2012). Öğretmen adaylarının Türkçeyle ilgili algılarının metaforlar yoluyla belirlenmesi: Atatürk Üniversitesi örneği. Uluslararası Cumburiyet Ë̆itim Dergisi, 1(1), 38-47.

Shuell, T. J. (1990). Teaching and learning as problem solving. Theory into Practice, 29(2), 102-108.

Smith, A. (2015). US smartphone use in 2015. Pew Research Center, 18-29.

Spitzer, M. (2015). M-Learning? When it comes to learning, smartphones are a liability, not an asset. Trends in Neuroscience \& Education, 4, 87-89

Tavşancıl, E. ve Aslan, E. (2001). İ̧erik analiz̨i ve uygulama örnekleri. İstanbul: Epilson Yayınları.

Toteja, R. ve Kumar, S. (2012). Usefulness of m-devices in education: A survey. Procedia-Social and Behavioral Sciences, 67, 538-544.

TUIK. (2015). Hanehalkı bilişim teknolojileri kullanım araștırması. [Online] Retrieved on 26- 03-2016, at URL: http:/ / www.tuik.gov.tr/PreHaberBultenleri.do?id=18660.

We are Social (2015), Global internet ve sosyal medya kullanic1 istatistikleri. http://www.slideshare.net/wearesocialsg/digital-social-mobile-in-2015, 26.03.2016 tarihinde erişildi.

Wentworth, D. K. ve Middleton, J. H. (2014). Technology use and academic performance. Computers \& Education, 78, 306-311.

Yıldırım, A. ve Şimşek, H. (2005). Sosyal bilimlerde nitel araştırma yöntemleri. Ankara: Seçkin Yayınc1lık.

Yob, I. M. (2003). Thinking constructively with metaphors. Studies in Philosophy and Education, 22, 127-138.

Yusufoğlu, Ş. Ö. (2017). Boş zaman faaliyeti olarak akıllı telefonlar ve sosyal yaşam üzerine etkileri: üniversite ögrencileri üzerine bir araştırma. İnsan ve Toplum Bilimleri Araştırmalar Dergisi, 6(5), 2414-2434.

\section{EXTENDED ABSTRACT}

A metaphor is considered to offer a mental framework for thinking about a phenomenon. Metaphors are reflecting the elements of the universe through their own filter of emotions and thoughts. Thus, one expresses the images of this world with his own perception. It is a powerful mental mapping and modeling mechanism for understanding and structuring the individual's own world. There are many studies on the theory that metaphors are formed in science, organizations change their strategic orientations, how employees perceive the organizations they work for, and how they provide data to the business world about how they act as mirrors to explain organizational change. In the field of education, there are many studies on how to use tools that facilitate children's learning, how teachers perceive their students, and how students perceive their lessons.

While the use of developing technology makes daily life easier, it is an undeniable fact that overuses affect people negatively. One of the good examples is that the computer is used more than necessary for the purpose. Overuse is an important problem that can lead to serious physical and psychological problems.

The aim of this study is to determine individuals' perceptions of internet, social world and smart phones through metaphors. Based on these perceptions, the effect and reflection of the individual on his / her life will be determined. For this purpose, the themes of the metaphors about social networks, internet connection and smart phones were determined according to the positive-negative and abstractconcrete distinction and the differences between the groups were investigated.

This research was designed and realized in descriptive model. The study was considered to be longitudinal and attention was paid to cover the basic (6-12 age), middle (6-12 age) and upper (13-19 age) age groups. Data were obtained by using Document Analysis technique in accordance with qualitative research method. A form was prepared by the researcher and used as a data collection tool.

"Social networks, Internet, My phone is a ............. for me because it is .........." sentences were given and blanks were filled by participants. They were asked to find a metaphor for each gap within 20 minutes and write a justification by completing the sentence with. 
In the first stage, the participants were ranked according to their groups. Then the metaphors created by the participants were sorted and coded alphabetically. Papers not explained why were excluded from the analysis.

Reasoned metaphors that will guide the data analysis process of the study are examined and the main themes to which they will be answered are determined.

In addition to the research group, the themes were examined unaware of the other four academicians who are experts in their fields. The statements were approved with one or two corrections. Content analysis technique was used to analyze the data obtained from the study.

When the sentences related to the social networks were examined, it was seen that more than half of the participants made the following statements; I don't use it, I had but I turned it off, I gave up, no.

Especially in the basic group, it can be said that negative perception has become widespread due to the denigration and prohibition of these practices aimed at protecting children. On the other hand, it is understood that individuals who make up the upper group get involved in individuals and subjects in social sharing networks and that negative perception is increased by being bored from the sharing. However, it has been determined that the individuals who form the middle group meet the need to express themselves freely through these social networks.

It is interesting to note that almost all of the perceptions about the Internet are positive and even perceived as the basic need, while the participants are generally cautious towards social networking.

It is understood that almost half of the participants perceive the smart phones as the need to connect and have fun. However, the dependency created by the means in question is undeniable. When they were not with them, they perceived themselves as dead, orphan, orphan and felt unhappy and insecure. In this context, it can be said that they have developed a sense of physical integration with mobile phones. This indicates an extremely disadvantageous addiction.

It is inevitable that the generation that opens their eyes to the world by being recorded with technological tools will internalize the technology. However, the response to intensive use of technology was not delayed and, as for other addictive substances, social awareness had to be increased in this area. In this context, it can be said that there is a parent who is more cautious about technology and tries to protect their children. When the metaphors of social networking, internet and smart phones are examined, the fact that the group producing the most negative metaphor is the main group can be interpreted as the reflection of these measures to children. In the positive sense, it was determined that the most intensive metaphor producing group was the middle group. Since the participants in this group were children in the age of self-knowledge, self-recognition, and self-acceptance as an individual, the parents reacted more strongly to the efforts of parents to remove them from the technology. It can be thought that the conscious awareness that makes itself felt in the high level participants has not matured yet in the middle group participants. Cigarette and tobacco addiction, Alcohol addiction, Substance addiction, Gambling addiction and Technology addiction are serious diseases. 